The book is lavishly illustrated throughout, with photographs and line diagrams, and in general the presentation is very good.

Some chapters of the book, judging by the content and reference lists, are years out of date. In a rapidly developing subject this is a serious defect, but it is to a large extent mitigated for at present the book has no competitors. Only the Russian Palaeopalynology has similar scope covering the same wide range in time and much the same fossils. The two books, however, complement rather than compete, for the Russian text deals only with the Soviet Union; the American book covers the rest of the world with emphasis on the United States and West Europe. Aspects of Palynology is therefore the first book in English to display the wide scope of modern palynology starting with the earliest fossils and continuing to the present day.

The book should be welcomed as a valuable contribution, elegantly advertising to students and non-specialists the quality and scale of modern palynology and, for these reasons alone, it ought to be included in geological and botanical libraries.

Charles Downie

\section{COLD LANDS}

\section{Geomorphology of Cold Environments}

By Jean Tricart. Translated by Edward Watson. Pp. xvi $+320+12$ plates. (Macmillan: London; St Martin's Press: New York, January 1970.) 80s.

French geomorphologists are very interested in the effect of climate on landforms. J. Tricart, one of the foremost French geomorphologists, wrote this book on cold climate landforms originally with A. Cailleux. The first joint edition of the work was published in two volumes, Le Modele Glaciaire et Nival and Le Modèle Periglaciaire. In 1963 Tricart published an abridged French edition in one volume, of which this present edition is a revised translation. Both original authors and the English translator are thoroughly familiar with their field of study and have wide field experience in many different areas. They therefore write with authority, but also with caution, pointing out where there are still uncertainties.

The book is divided into three parts. The first deals with the spatial aspects of present day glaciers and frost climates and the pattern of Quaternary glaciation. There is a brief section on the origin of ice sheets. The second section, the best part of the book, deals with periglacial processes and the resulting landforms. It is divided into four chapters, discussing soil formation, microrelief due to frost, development of slopes and plurizonal processes. A wide range of phenomena are covered, including the intriguing patterns that are so characteristic of some periglacial areas. The last chapter deals with the influence of a cold climate on river and wind action. The six chapters in part three are devoted to glacial processes and landforms. They cover glacier dynamics, the role of snow, the development of the glacier bed, the ice margin, which covers glacifluvial processes, multiple glacial effects and the final chapter deals largely with sea level changes resulting from glaciation.

The book is short and the approach is largely descriptive. It is a pity that there is so little discussion of such topics as the mechanism of glacier flow, to which only three pages are devoted. These include a description of extrusion flow, which has long been regarded as physically unsound. Bccause of the lack of an adequate physical background, the explanations of many of the features are not fully satisfying. This applies throughout the book, but particularly in part three. Drumlins, for example, have only one page and no adequate explanation of their formation is given. There is little information on the study of glacial deposits, by till fabric analysis for instance. Stone shape values are mentioned, but the indices are not explained.

There are thirty-three figures, about a quarter of which are drawings from photographs. Fig. 3 has a faulty key. There are eighteen good photographs. The 550 references are collected at the end. They are divided into topies, according to the chapter subdivisions for the most part. The list is comprehensive and reasonably up to date, but many are not directly referred to in the text. The book is well written and produced, but it covers too large a field in too short a space to do other than provide a descriptive account of the many and varied forms characteristic of the cold environments, present and past.

C. A. M. KING

\section{HOW TO BUILD AN OBSERVATORY}

\section{Notes on Geomagnetic Observatory and Survey Practice}

By K. A. Wienert. (Earth Sciences, Vol. 5.) Pp. 217. (Unesco: Paris; HMSO : London, 1970.) 34 francs; $51 s$; $\$ 8.50$.

THE origins of this book are described in the introduction. Between 1964 and 1968, Unesco and the World Magnetic Survey Board sent missions to many countries to assess the state of geomagnetic work, in particular the running of magnetic observatories. The experts who carried out this mission all drew attention to the need for an up to date practical handbook on geomagnetic observatory and survey practice, intended for the use of scientific and technical personnel engaged both in observatory and field work. This book was written to fill that gap.

Dr Wienert begins by discussing the problems of choosing a site for an observatory, and of constructing a suitable building to house the magnetometers. By far the largest section of the book is concerned with the description of the standard observatory instruments (particularly those used in making absolute measurements), of the methods of observation, and of techniques of reducing the data. It struck me that diagrams illustrating the chief features of the magnetometers described (for example, magnetic theodolite, QHM, earth inductor, BMZ), would have helped to make the text more intelligible, but presumably a technician would have the instruments themselves, or at least the handbooks, in front of him.

In addition to describing the classical types of magnetometer, Wienert also devotes some space to the proton magnetometer, and to the problem of determining com. ponents of the magnetic field using an instrument that measures only the scalar magnitude of the field. In the section on the recording of time variations he does not, however, consider the automatic digital forms of recording which are particularly suited to the proton and rubidium magnetometers, but restricts himself to the photographic recording method used by the standard La Cour magnetograph.

The book is well produced, and is laid out in the form of notes for easy reference. A very useful feature is the large number of examples showing the correct layout of recorded data and of the subsequent calculations. Although the book is clearly not intended to be read as a whole, I found it surprisingly easy going, punctuated by occasional asides which are both instructive and amusing. Wienert's remarks about the advisability of assuring villagers that one has nothing to do with the income tax office are particularly engaging.

Although the book will probably be limited in its appeal to people intimately connected with the routine of making magnetic measurements, to them it must be extremely valuable. If they follow the author's instructions they will be able to feel that, although it is not in mortals to command success, they will have deserved it.

R. J. BANKS 